\title{
High-resolution grids of gravimetric terrain corrections and complete Bouguer gravity reductions over Australia
}

\author{
J F Kirby
}

Department of Spatial Sciences

Curtin University of Technology

Bentley WA 6102

Australia

Tel 0892667701

Fax 0892662703

jfk@vesta.curtin.edu.au

\section{W E Featherstone}

Department of Spatial Sciences

Curtin University of Technology

Bentley WA 6102

Australia

Tel 0892662734

Fax 0892662703

W.Featherstone@curtin.edu.au

Left running heading: Kirby and Featherstone

Right running heading: Australian Bouguer reductions 


\begin{abstract}
Complete Bouguer corrections have been computed for the entire Australian continent on a 9 arc-second grid ( $250 \mathrm{~m})$ from version 2 of the GEODATA digital elevation model of Australia. This includes the Bouguer plate correction to the geoid and the terrain correction residual to this plate out to a radius of $50 \mathrm{~km}$ (beyond Hammer zone M). A constant topographic density of $2670 \mathrm{~kg} \cdot \mathrm{m}^{-3}$ has been used in both correction terms. The terrain correction was computed using a two-dimensional fast Fourier transform algorithm. The complete Bouguer corrections can be interpolated from this grid and applied to free-air gravity anomalies to yield complete Bouguer gravity anomalies. Alternatively, the terrain corrections can be applied to existing simple Bouguer gravity anomalies to yield complete Bouguer gravity anomalies.
\end{abstract}

Key words: Bouguer correction, terrain correction, gravity anomaly, digital elevation model, FFT.

\title{
INTRODUCTION
}

The complete Bouguer gravity reduction is required to remove the high degree of correlation of the free-air gravity anomaly with elevation prior to geophysical interpretation. This comprises the simple Bouguer gravity reduction and the gravimetric terrain correction. However, terrain corrections are not available for most of the Australian Geological Survey Organisation's (AGSO’s) gravity database, with terrain corrections only being available in some areas of Tasmania (eg., Murray, 1997). Therefore, most users of these data have to compute and apply their own terrain corrections in most areas.

Kirby and Featherstone (1999) computed the first continent-wide grid of gravimetric terrain corrections over Australia. This used version 1 of the GEODATA 9 arc-second digital elevation model (DEM) of Australia (Carroll and Morse, 1996). However, the spatial resolution of these terrain corrections had to be reduced to 27 arc-seconds. This 
choice was based upon the observation that extremely large terrain corrections (exceeding $250 \mathrm{mGal}$ ) resulted in some areas. These are clearly anomalous given the relatively benign Australian topographic morphology. At the time, this was attributed to a numerical instability in the Moritz (1968) algorithm for the terrain correction (cf. Martinec et al., 1996). Although these terrain corrections were supplied to AGSO, they do not appear to have yet been included in the national gravity database.

It has since been discovered (Kirby and Featherstone, 2001) that these excessive terrain correction values were caused by anomalously large horizontal gradients (up to 76 degrees) in version 1 of the GEODATA 9 arc-second DEM, and not necessarily an instability in Moritz's algorithm. Incorrect flow directions of the stream data used to constrain the DEM had caused these errors (Hutchinson, 2000 pers. comm.). Version 2 of the GEODATA 9 arc-second DEM was released in early 2001 (http://www.auslig.gov.au/products/digidat/ dem.htm), and these errors are thought to have been corrected. This allows the full spatial resolution of the DEM to be used to compute terrain corrections, which is reported in this paper. This new, high-resolution grid of terrain corrections will be supplied to AGSO for evaluation and possible inclusion in the national gravity database.

\section{CONCEPTUAL MODELS}

\section{The simple Bouguer gravity reduction}

The simple Bouguer reduction is often used as a standard model to attempt to remove most of the gravitational attraction of topographic masses from gravity observations prior to geophysical interpretation. This must be applied in conjunction with the free-air gravity reduction and normal gravity on the reference ellipsoid (latitude correction) to compute the simple Bouguer gravity anomaly. Rigorous formulae for the free-air and normal gravity corrections are given in Featherstone and Dentith (1997). However, there are two conceptual models for the simple Bouguer correction - a planar model (the Bouguer plate) and a spherical model (the Bouguer shell and Bouguer cap). 
The Bouguer plate reduction is in widespread use probably because it is relatively straightforward to derive and thus appears in many textbooks. However, an infinitely extending plate poorly approximates the shape and thus gravitational attraction of the Earth (cf. Qureshi, 1976). Accordingly, several authors (eg. Ervin, 1977; Chapin, 1996; Karl, 1971; LaFehr, 1991, 1998; Talwani, 1998; Smith et al., 2001; Vanicek et al., 2001) have all proposed the use of a spherical model for the simple Bouguer correction.

However, the application of the spherical Bouguer correction over a cap of $166.7 \mathrm{~km}$ (the outer radius of the Hayford-Bowie system) is approximately equal to the Bouguer plate correction ( $2 \pi G \rho \mathrm{mGal} . \mathrm{m}^{-1}$ ), depending on elevation (cf. Talwani, 1998; LaFehr, 1998). The planar Bouguer correction has been adopted in this study for the sake of consistency with most current practice. In addition, this planar model is consistent with the gravimetric terrain correction that will be computed (described later).

Possibly the overriding limitation to the Bouguer plate/cap reduction is the accurate estimation of the topographic mass-density (eg. LaFehr, 1991; Huang et al., 2001). Incorrect estimates of the topographic mass-density cause distortions in the simple Bouguer gravity anomalies. These are often highly correlated with geological structures, thus causing problems in subsequent geophysical interpretations and forward models. However, a continent-wide digital density model is not yet available for Australia. Therefore, the constant Bouguer reduction density of $2670 \mathrm{~kg} \cdot \mathrm{m}^{-3}$ will be used throughout this paper.

\section{The terrain 'correction'}

The simple Bouguer anomaly (plate/cap/sphere) must be refined by adding a component due to the topographic masses unaccounted for above the station, and again adding a component from any excess mass existing below the station where no mass is actually present. That is, the terrain correction is always positive (for the planar model, since the terrain correction can sometimes be negative for the spherical models). If the terrain correction due to the topography residual to the Bouguer plate/cap/shell is not applied, its gravitational signal contaminates the derived gravity anomaly, thus leading to a possible misinterpretation of the sub-surface structure. 
The complete/refined Bouguer correction comprises the simple Bouguer correction and the terrain correction. This is applied to the free-air gravity anomaly to yield the complete/refined Bouguer gravity anomaly. The terrain correction is used to model and remove the gravitational effects of the topography residual to the Bouguer plate/cap/shell. Of course, the terrain correction used must be consistent with the spherical or planar Bouguer model (cf. LaFehr, 1991; Takin and Talwani, 1996; Vanicek et al., 2001). The planar, linear approximation of the terrain correction proposed by Moritz (1968) will be used in this study, which is consistent with the Bouguer plate model.

Historically, terrain corrections were computed using Hammer (1939) charts about each gravity observation point. This is an extremely time-consuming process, and was often neglected for all but the most rugged topographic morphology. For instance, terrain corrections have only been applied to the Australian gravity database in Tasmania (eg. Murray, 1997). However, terrain corrections can now be computed efficiently from the regular grid of (mean) elevations provided by a DEM (eg., Cogbill, 1990; Ma and Watts, 1984). After some approximation and regularisation, this computation can be accelerated by several orders of magnitude using the two-dimensional fast Fourier transform or 2D-FFT (eg. Forsberg, 1985; Sideris, 1985; Schwarz et al., 1990; Li and Sideris, 1994). Exactly the same 2D-FFT-based computational methods as described in Kirby and Featherstone (1999) were used for this study.

The primary limitation to the use of a DEM, which normally models only the mean elevation in a grid cell, to calculate terrain corrections is that near-meter effects are omitted (cf. Leaman, 1998; Nowell, 1999). Therefore, the terrain corrections computed in this study represent a band-width-limited signal for gravitational terrain effects from between $\sim 250 \mathrm{~m}$ and $\sim 50 \mathrm{~km}$. This is roughly equivalent to terrain corrections from Hammer zones $\mathrm{D}$ to beyond $\mathrm{M}$. If the users of this grid require near-meter terrain corrections, they need only apply them residual to the mean elevation provided by version 2 of the GEODATA 9 arc-second DEM and out to a distance of 250m (cf. Tsoulis, 2001). This computational strategy offers a considerable saving in time and effort, as well as the need for a very high-resolution terrain model over a large area. 
It is also acknowledged that flat-topped prisms (i.e., due to the mean heights in a DEM) do not necessarily accurately model the actual topographic morphology. More sophisticated models have been proposed (eg., Smith, 2000). However, these are not suited to practical computation on a continent-wide scale, especially at a high spatial resolution. The benefit of using the modified Moritz algorithm is that is suited to computation by the 2D-FFT. Moreover, algorithmic approximations have to be balanced against the precision of the DEM heights (Hutchinson, 2001) and the assumption of a constant topographic mass-density. Therefore, there is not necessarily any gain in accuracy by using a more sophisticated model, where a simple and fast approximation is adequate.

A final consideration is the use of the gravitational constant, $G$ (cf. Talwani, 1998; LaFehr, 1998). The most recent estimate of $G=6.67259 \times 10^{-11} \mathrm{~kg}^{-1} \cdot \mathrm{m}^{3} \mathrm{~s}^{-2}$ (Mohr and Taylor, 2000) will be used in all the computations.

\section{DATA AND RESULTS}

The dataset used in this study is version 2 of the GEODATA 9 arc-second DEM of Australia (Hutchinson, 2001; http://www.auslig.gov.au/products/ digidat/dem.htm), which is distributed by the Australian Surveying and Land Information Group (AUSLIG). In this DEM, the heights above mean sea level are represented on a regular grid, and the average elevation within each grid cell estimated. This DEM was constructed from over one million spot heights held by AUSLIG, elevations held in the AGSO gravity data-base, and some airborne altimetry (Hutchinson, 2001). The vertical datum is assumed to be the Australian Height Datum (Roelse et al., 1971). The gridding was performed using the Australian National University’s drainage-enforcing algorithm (Hutchinson, 1989).

The computational procedure used for this new 9 arc-second grid of Australian terrain corrections is exactly the same as that used by Kirby and Featherstone (1999). Therefore, the reader is referred to this paper for details on the algorithms and their numerical implementation in the 2D-FFT. The additional consideration in this paper is 
the computation of Bouguer plate corrections for each of the DEM elements. It is argued that this samples areas where gravity observations have not been made, and is thus more representative of the total gravitational effect of the topography (cf. Featherstone and Kirby, 2000). In addition, these Bouguer plate corrections and the gravimetric terrain corrections are totally consistent. These can be interpolated from the grid and applied to free-air gravity anomalies computed at the observation locations. Alternatively, the terrain corrections can be interpolated from the grid and applied to the simple Bouguer gravity anomalies computed at the observation locations.

Table 1 shows the statistics of the DEM grid, the simple Bouguer reductions, the terrain corrections and the complete Bouguer reductions, all at a spatial resolution of 9 arcseconds. Colour images of the new grids of terrain corrections and complete Bouguer reductions, generalised onto a lower resolution grid for display purposes, are shown in Figures $1 \mathrm{a}$ and $1 \mathrm{~b}$ respectively. As expected, these highlight the correlation with steep topographic gradients. Areas of note are, from west to east: the Darling Ranges near Perth and the Margaret River area; the Hamersley Range in northern Western Australia; the Kimberley; the MacDonnell Range in the centre; the Barkly Tableland to Mount Isa, just south of the Gulf of Carpentaria; the Flinders Range near Adelaide; all of the Great Dividing Range; and Tasmania. Also worthy of note is the demarcation of the Nullarbor Plain, north of the Bight.

\begin{tabular}{|l|r|r|r|r|r|}
\hline \multicolumn{1}{|c|}{ data } & \multicolumn{1}{c|}{ max } & \multicolumn{1}{c|}{ min } & \multicolumn{1}{c|}{ mean } & \multicolumn{1}{c|}{ std } & \multicolumn{1}{c|}{$R M S$} \\
\hline DEM (m) & 2228.0 & -16.0 & 272.0 & 191.5 & 332.7 \\
\hline SBC (mGal) & 1.8 & -249.4 & -30.5 & 21.4 & 37.2 \\
\hline TC (mGal) & 86.9 & 0.0 & 0.16 & 0.68 & 0.70 \\
\hline CBC (mGal) & 20.7 & -231.6 & -30.3 & 21.2 & 37.0 \\
\hline
\end{tabular}

Table 1. Descriptive statistics of the DEM (metres), the simple Bouguer correction (SBC) applied to the DEM elements, the gravimetric terrain correction (TC), and the reconstituted complete Bouguer correction (CBC) (mGal), all at a spatial resolution of 9 arc-seconds 


\section{DISCUSSION}

The generation of a 9 arc-second spatial resolution Australian digital elevation model by AUSLIG has had significant impact in the geosciences. Two of these are described here, namely the development of similar resolution digital models of the terrain correction and complete Bouguer anomaly. Regarding the former, given the lack of widely available terrain corrections, it is advantageous to have an accessible database of these, particularly for regional gravity surveys and geoid modelling. By interpolation from these grids, it is a simple procedure to apply the Bouguer or terrain correction to existing or new gravity data.

\section{ACKNOWLEDGMENTS}

This research is funded as part of Australian Research Council large grant A39938040 to Featherstone and Curtin University Postdoctoral Fellowship to Kirby. We would like to thank the Australian Surveying and Land Information Group (AUSLIG) for providing version 2 of the GEODATA DEM of Australia. Finally, thanks go to the reviewers for their constructive critique of this manuscript.

\section{REFERENCES}

Carroll D, Morse MP (1996) A national digital elevation model for resource and environmental management, Cartography, 25(2): 395-405.

Chapin DA (1996) The theory of the Bouguer gravity anomaly: A tutorial, The Leading Edge, May, 361-363.

Cogbill AH (1990) Gravity terrain corrections computed using digital terrain models, Geophysics, 45: 109-112.

Ervin CP (1977) Theory of the Bouguer anomaly, Geophysics 42(7): 1468.

Featherstone WE, Dentith MC (1997) A geodetic approach to gravity reduction for geophysics, Computers and Geosciences, 23: 1063-1070. 
Featherstone WE, Kirby JF (2000) The reduction of aliasing in gravity anomalies and geoid heights using digital terrain data, Geophysical Journal International, 141, 204212.

Forsberg R (1985) Gravity field terrain effect computations by FFT, Bulletin Géodésique, 59: 342-360.

Hammer S (1939) Terrain corrections for gravimeter stations, Geophysics, 4(3): 184194.

Huang J, Vanicek P, Pagiatakis SD, Brink W (2001) Effect of topographical density on geoid in the Canadian Rocky Mountains, Journal of Geodesy, 74(11/12): 805-815.

Hutchinson MF (1989) A new procedure for gridding elevation and stream line data with automatic removal of spurious pits, Journal of Hydrology, 106: 211-232.

Hutchinson MF (2000) Personal Communication, Centre for Resource and Environmental Studies, Australian National University, Canberra.

Hutchinson MF (ed) (2001) GEODATA 9 second DEM (version 2): Data users guide, Australian Surveying and Land Information Group, Canberra, 46pp. http://www.auslig.gov.au/products/digidat/9sdemv2userguide.pdf

Karl JH (1971) The Bouguer correction for the spherical Earth, Geophysics, 36(4): 761762.

Kirby JF, Featherstone WE (1999) Terrain correcting the Australian gravity data base using the national digital elevation model and the fast Fourier transform, Australian Journal of Earth Sciences, 46(4): 555-562.

Kirby JF, Featherstone WE (2001) Anomalously large gradients in the GEODATA 9 SECOND Digital Elevation Model of Australia, and their effects on gravimetric terrain corrections, Cartography, 30(1): 1-10.

LaFehr TR (1991) Standardisation in gravity reduction, Geophysics, 56(8): 1170-1178.

LaFehr TR (1998) On Talwani’s “Errors in the total Bouguer reduction” Geophysics, 63(4): 1131-1136.

Leaman DE (1998) The gravity terrain correction - practical considerations, Exploration Geophysics, 29(3/4): 476-471.

Li YC, Sideris MG (1994) Improved gravimetric terrain corrections, Geophysical Journal International, 119: 740-752

Ma XQ, Watts DR (1984) Terrain correction program for regional gravity surveys. Computers and Geosciences, 20(10): 961-972. 
Martinec Z, Vanicek P, Mainville A, Veronneau M (1996) Evaluation of topographical effects in precise geoid determination from densely sampled heights, Journal of Geodesy, 70(11): 746-754.

Mohr PJ, Taylor BN (2000) The fundamental physical constants, Physics Today, 53(82), 6-13.

Moritz H (1968) On the use of the terrain correction in solving Molodensky’s problem, OSU Report No. 108, Department of Geodetic Science and Surveying, Ohio State University, Columbus.

Murray AS (1997) Thee Australian national gravity database, AGSO Journal of Australian Geology and Geophysics, 17(1): 145-155.

Nowell DAG (1999) Gravity terrain corrections - an overview, Journal of Applied Geophysics, 42: 117-134.

Qureshi IR (1976) Two-dimensionality on a spherical Earth - a problem in gravity reductions, Pure and Applied Geophysics, 114: 91-93.

Roelse, A., H.W. Granger and J.W. Graham (1971) The adjustment of the Australian levelling survey - 1970-71. Report 12, National Mapping Council, Canberra.

Schwarz K-P, Sideris MG, Forsberg R (1990) The use of FFT techniques in physical geodesy, Geophysical Journal International, 100(3): 485-514.

Sideris MG (1985) A fast Fourier transform method of computing terrain corrections, manuscripta geodaetica, 10(1): 66-73.

Smith DA (2000) The gravitational attraction of any polygonally shaped vertical prism with inclined top and bottom faces, Journal of Geodesy, 74(5): 414-420.

Smith DA, Robertson DS, Milbert DG (2001) Gravitational attraction of local crustal masses in spherical coordinates, Journal of Geodesy, 74(11/12): 783-795.

Takin M, Talwani M (1966) Rapid computation of the gravitational attraction of the topography on a spherical Earth, Geophysical Prospecting, 24: 119.

Talwani M (1998) Errors in the total Bouguer reduction. Geophysics, 63(4): 1125-1130.

Tsoulis D (2001) Terrain correction computations for a densely sampled DTM in the Bavarian Alps, Journal of Geodesy, 75 (5/6): 291-307

Vanicek P, Novak P, Martinec Z (2001) Geoid, topography, and the Bouguer plate or shell, Journal of Geodesy, 75(2/3): 210-215. 


\section{FIGURE CAPTIONS}

\section{FIGURE 1.}

Figure 1a. Image of the 9 arc-second terrain corrections over Australia, illuminated from the north-east. Units in mGal. Mercator projection from the GRS80 ellipsoid.

Figure 1b. Image of the 9 arc-second complete Bouguer gravity reductions over Australia, illuminated from the north-east. Units in mGal. Mercator projection from the GRS80 ellipsoid. 


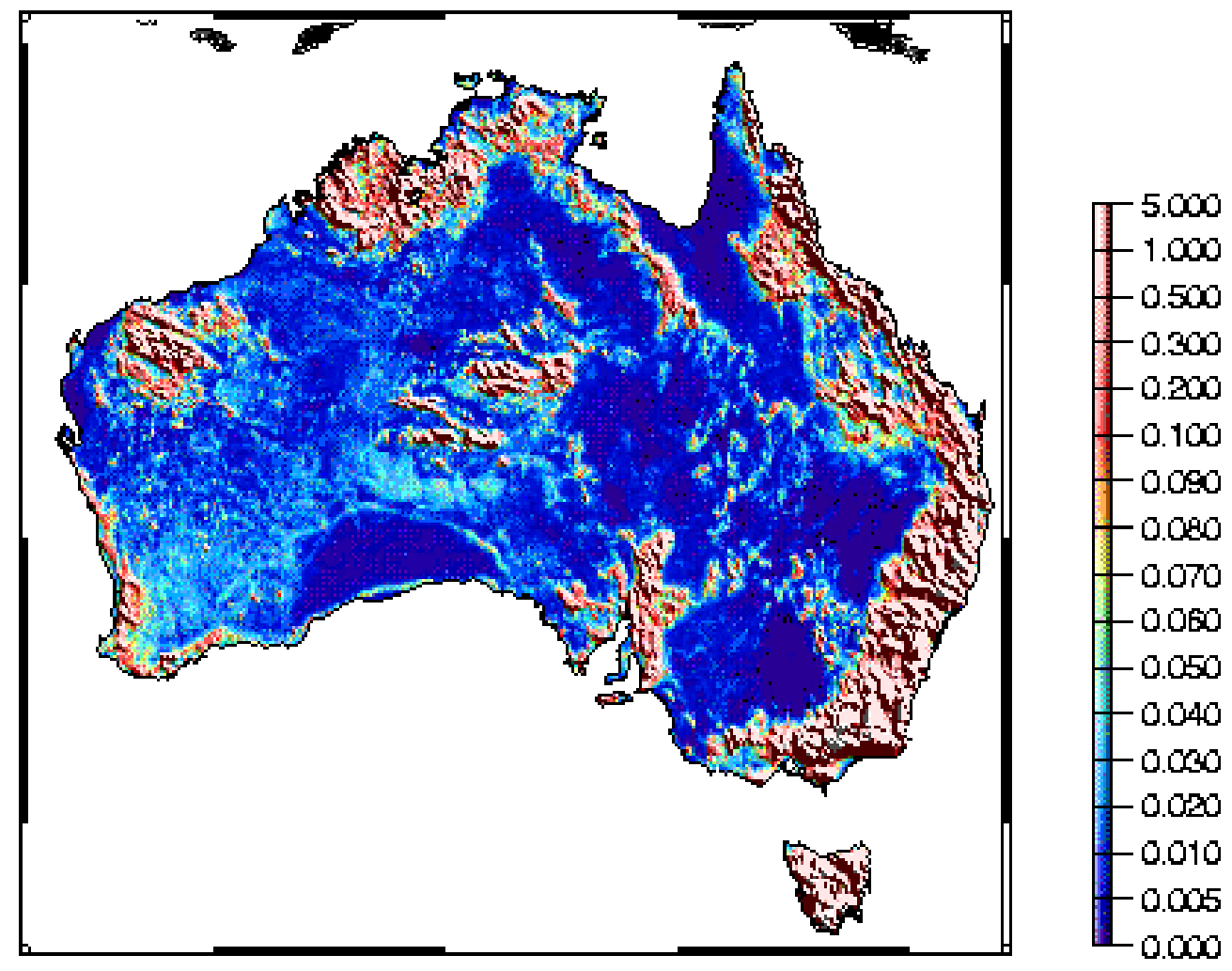

Figure 1a. Image of the 9 arc-second terrain corrections over Australia, illuminated from the north-east. Units in mGal. Mercator projection from the GRS80 ellipsoid.

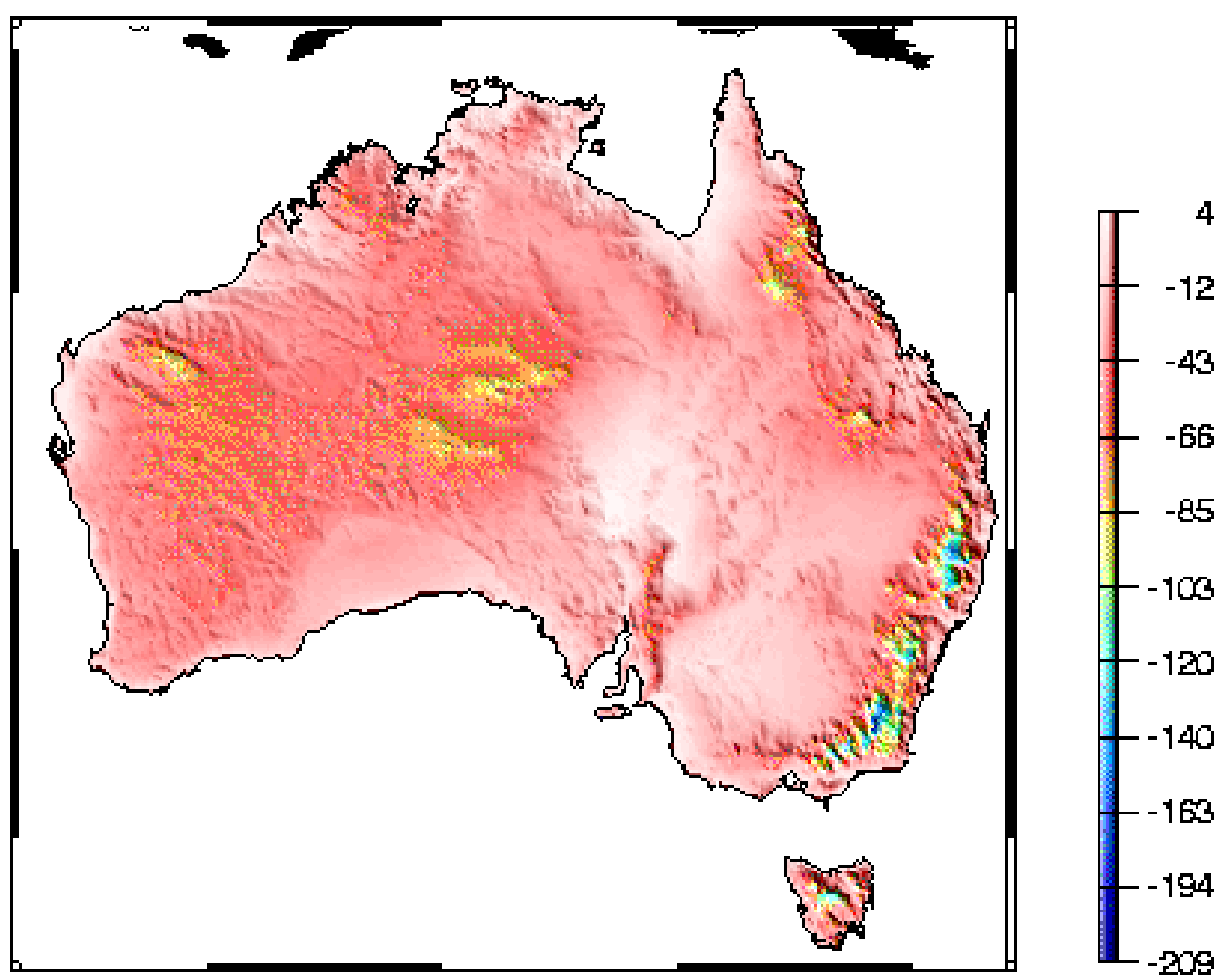

Figure 1b. Image of the 9 arc-second complete Bouguer gravity reductions over Australia, illuminated from the north-east. Units in mGal. Mercator projection from the GRS80 ellipsoid. 